\title{
An innovative hybrid insulation switch to enable/disable electrical loads without overvoltages
}

\author{
Konrad Zajkowski ${ }^{1, *}$ \\ ${ }^{1}$ Koszalin University of Technology, DP of Energy, 15-17 Raclawicka St. 75-620 Koszalin, Poland
}

\begin{abstract}
This article describes an innovative project for the design of a low voltage switch to enable/disable electrical devices from an AC source, which is characterised by the absence of arc ignition. When powered off, this device is a galvanically separated of the receiver from the power source. The proposed hybrid interaction has two switches: the insulating switch made of mechanical contacts and the current switch made of elements from power electronics. The absence of arc ignition increases the equipment uptime and improves the comfort-powered receiver and equipment located nearby.
\end{abstract}

\section{Introduction}

The generation of overvoltage, which ignites the arc on the switch contacts, is accompanied by disconnection of the load from the electrical network. The problem of overvoltages is up-to-date and often discussed in the literature [1-4]. The immediate cause of the overvoltage is a disconnected non-zero current, which flows through the inductance [5-7]. This is a consequence of the continuation of the energy function as described by equations of current through the coil.

A model consisting of an AC power source, power line, and energy receiver includes several inductances connected in series. They represent the nature of the line, the receiver and the source [8-10]. The resultant inductance is equal to the sum of all inductances in a closed circuit. This means that the electric arc generation will be accompanied by the character for any receiver, including the resistive.

For the contacts in the switch, while operating an AC current circuit switch with a receiver of any type, the electric arc impacts can be observed on its surface. A repeated interaction electrical arc reduces the ability of the working device, manifested by increasing resistance, arcing and sticking contacts. When using a conventional installation of low voltage switches, there is a destruction of the working layer of these contacts. This results in a deterioration of the electrical conductivity in the "ON" position. Moreover, the generation of the electric arc on the connector contacts adversely affects the operation of the other devices in the vicinity of the switch [11]. Frequent commutation causes harmonics in the power supply circuit of other technical receivers [12].

The construction of conventional electrical switches is based on mechanical contacts that are exposed to all of the negative effects of the electric arc. The electric arc is not observed, when commutation is made at the instantaneous value of current equal to $i(0)=0$. The power electronic switch is built with a triac.

Switching by power electronics has been used in systems of higher voltages to date. They support the switching process but do not provide the isolation of the receiver from the phase conductor in a disconnected state.

Switches are used at higher voltages [13]. Thyristor stacks are connected in parallel to the mechanical switches (Fig. 1).

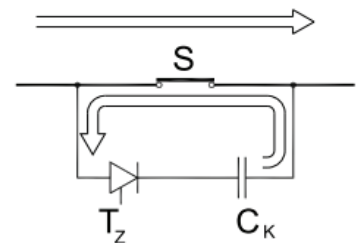

Fig. 1. An Electrical diagram of an exemplary thyristor switch; $\mathrm{S}$ - mechanical switch, $\mathrm{T}_{Z}$ - thyristor stacks, $\mathrm{C}_{\mathrm{K}}$ - commutation capacitor [13].

This configuration results in no electric arc, but to fulfil the required isolation from the source of the receiver in the OFF state, it must be liberated from an additional switch, which is connected in series with the thyristor stack. To achieve the primary shock protection, the isolation should be in the "OFF" state.

\section{Technical description of the solution}

The procedure for eliminating the phenomena of electric arc ignition tends to improve the switching capacity of the contacts, extends the uptime and improves the comfort facilities located nearby. Additionally, is possible the work of this low-voltage switch in an environment exposed to the appearance of explosive vapours.

The reduction of the electric arc is possible by using

\footnotetext{
* Corresponding author: konrad.zajkowski@tu.koszalin.pl
} 
one or several methods simultaneously to reduce the overvoltages:

- A changing environment that surrounds the switch contacts (neutral gases or vacuum),

- Use of non-linear surge arresters,

- A change in the nature of the receiver by reducing the impact of induction,

- Commutation at the time when the current value is zero.

It is possible to reduce the arc ignition when commutation is performed at a time when the sine wave current passes through zero. A power electronic component that causes the disconnection of the sinusoidal current at a natural zero crossing of the current is a triac with an RC suppressor. The triac is turned $\mathrm{ON}$ by the gate current and is turned OFF when the anode current is zero.

Each commutation in a non-zero current introduces an additional harmonic distortion to the mains. The $\mathrm{ON}$ switch was held at the time of transition for the sinusoidal current through zero and requires a specialised system to start the gate current in the triac, which is synchronised with the detection of the zero anode current.

Electronic power components that are in a disconnected state do not cause the separation of the receiver from the phase conductor. To meet this requirement, the triac must cooperate with the mechanical contacts. This hybrid switch is the subject of this study.

The advantages of this method are:

- Switching operations, i.e., ON and OFF are held at the instantaneous current value equal to zero,

- No generation of additional harmonic distortion in the current waveform,

- Total absence of an electric arc during switching,

- Extension time without a failure switch,

- Increase the switching ability of the device,

- Improve the comfort of work devices that operate in the vicinity,

- Separation of the receiver from the phase conductor in the OFF state,

- Increasing the life of the receiver by reducing the inrush current during cold start,

- This device does not receive energy from a source in the OFF state.

The disadvantages are:

- Increasing the complexity of the switch and the cost of its production,

- Reduction in the amplitude of the sine wave voltage that powers the receiver.

The separation of the receiver in the OFF state and the absence of an electric arc in commutation are feasible in a hybrid system as shown in Fig. 2 .

The five-layer thyristor serves as an element which turning OFF the current flowing through the receiver when the instantaneous value of current is equal to zero. However, the $\mathrm{ON}$ function is a thyristor with the detectors for the zero current crossing. The function for the circuit isolator is a SB mechanical switch. The condition for the proper interaction of the two switches is the correct sequence of actions.

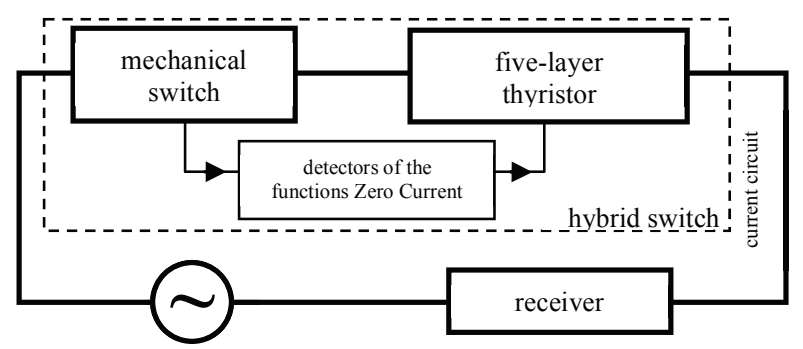

Fig. 2. A block diagram of the hybrid switch to connect the source and receiver.

The switching ON procedure should be performed in the following sequence (Fig. 3):

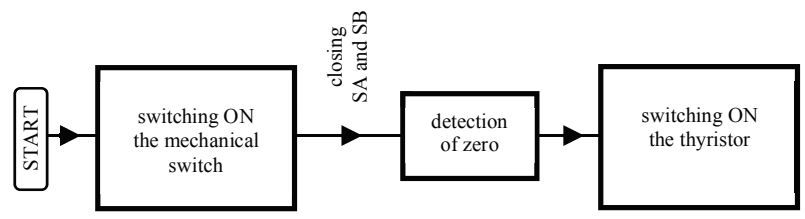

Fig. 3. The algorithm procedure for switching $\mathrm{ON}$ the hybrid switch.

The switching OFF procedure should be performed in the following sequence (Fig. 4):

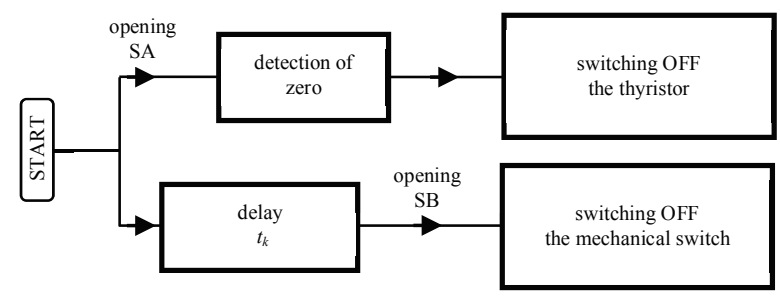

Fig. 4. The algorithm procedure for switching OFF the hybrid switch.

Disconnecting the SB mechanical switch should occur after the moment of time in which the sine wave current passes through zero (there will be an activation switch thyristor). For safety reasons, the delay time $t_{k}$ should be in the range:

$$
2 s \geq t_{k} \geq 1.1 \cdot t_{\min }
$$

where the $t_{\min }$ delay value depends on the frequency power source, and it is determined from the relationship:

$$
t_{\min }=\frac{1}{2 f}=\frac{1}{2 \cdot 50 H z}=0.01 \mathrm{~s} .
$$

\subsection{Implementation of the mechanical system}

The mechanical system is composed of an assembly of two bistable mechanical switch, current switch SB and auxiliary switch SA, which initiates the procedure for 
commutation (Fig. 5a).

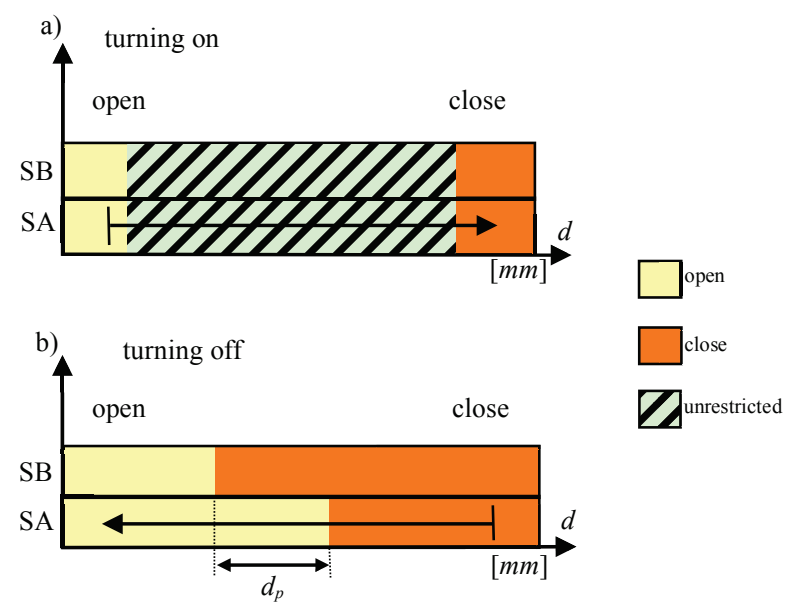

Fig. 5. Draft of the mechanical switch contacts: on the turning ON process a), on the turning OFF process $b$ ).

In the process of switching OFF, both mechanical contacts are moved using a common mechanism that provides the $t_{k}$ time offset between the opening of the contact SB and contact SA (Fig. 5c). In the process of switching ON (Fig. 5b), a special time offset is not required between commutations $\mathrm{SA}$ and $\mathrm{SB}$. The distance $d_{p}$ must be chosen so that at a certain speed of movement, the mechanism has met condition (1).

\subsection{Implementation of the electronic part of the device}

The Triac switch (4 in Fig. 6) was built with the power electronic element $\mathrm{T}_{1}$ type BTA16/600 that works with control triac $\mathrm{T}_{2}$ type MOC3063.

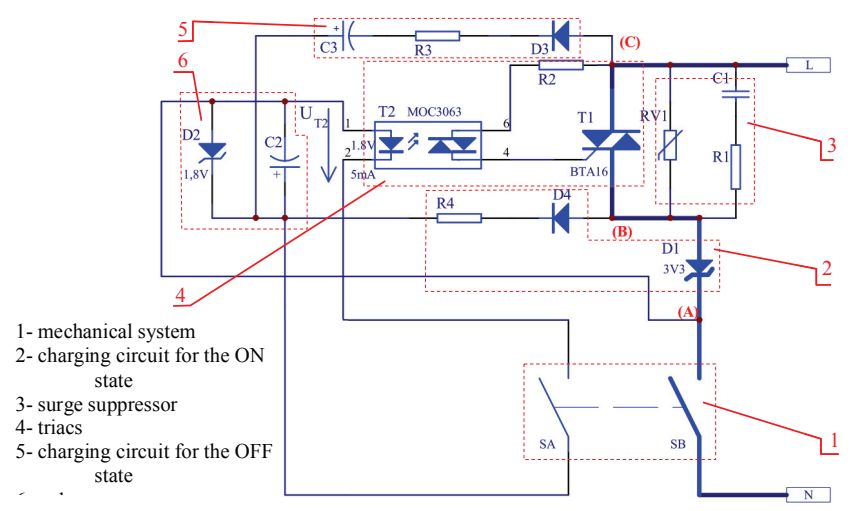

Fig. 6. Scheme of system for the hybrid electronic switch.

The procedure for turning ON this system begins after switches SA and SB are closed. The sequence and time shifts between the activation of SA relative to SB (according to Fig. 5b) do not affect the action of the system. The start of the switching ON procedure is possible only after the closure of two components: SA and SB. After closing SA and SB, switch $\mathrm{T}_{1}$ is opened, the current flowing through the diode $\mathrm{D}_{1}$ is equal to zero and the $U_{B A}$ voltage drop on the diode is also equal to zero.

In this case, the power source (2 in Fig. 6), which is built with the elements $D_{1}, D_{4}$ and $R_{4}$, is deactivated. The current flowing through $\mathrm{D}_{4}$ and $\mathrm{R}_{4}$ is equal to zero. The $\mathrm{D}_{1}$ diode does not have the flowing energy needed to charge the voltage source (6 in Fig. 6) that is constructed with diode $\mathrm{D}_{2}$ and capacitor $\mathrm{C}_{2}$. In the absence of the $U_{C_{2}}$ voltage on capacitor $C_{2}$, both the $T_{1}$ and $T_{2}$ triacs are in an open state. Opening element $\mathrm{T}_{1}$ allows the observation of the entire power supply voltage $U_{p}$ between points $\mathrm{C}$ and $\mathrm{A} U_{C A}=U_{p}$. Through diode $\mathrm{D}_{3}$, which acts as a rectifier, the current begins to flow in one direction. The value of this current depends on the values of the resistor $\mathrm{R}_{3}$ and the capacitor $\mathrm{C}_{3}$. This current begins charging capacitor $\mathrm{C}_{2}$ up to the zener voltage for diode $\mathrm{D}_{2}$. When the contact SA is closed, the $U_{C 2}$ source voltage activates the starting procedure for the triac $T_{2}$. Optotriac MOC3063 is equipped with the zero crossing detection of the sine wave of current, and the triac $T_{1}$ will be activated only at the time of the zero crossing for the sine wave of current flowing through the receiver. Because of the activation of the triac $\mathrm{T}_{1}$, the voltage $U_{C B}$ starts to drop to approximately $1.5 \mathrm{~V}$, which corresponds to the voltage drop at the closed thyristor. With such a small voltage value, the current flowing through diode $\mathrm{D}_{3}$ is zero. With the active key $\mathrm{T}_{1}$, the current flowing through the diode $\mathrm{D}_{1}$ will determine the voltage drop $U_{B A}$ at the level of the zener voltage of the diode. The nonzero voltage $U_{B A}$ causes a unidirectional flow of current through diode $\mathrm{D}_{4}$ and resistor $\mathrm{R}_{4}$. These components are responsible for the power supply voltage source (6 in Fig. 6) when the key $T_{1}$ is in the active state. As a result, diode $D_{1}$ is included in series with the receiver to reduce the voltage drop on the receiver (in the negative half of the sinusoid for a value of $0.7 \mathrm{~V}$ and in the positive half of the sinusoid for a value equal to the zener voltage of the diode).

The shutdown procedure begins after opening contact SA (according to Fig. 5c) - that is, after the $t_{a}$ time that is required for its opening procedure, counting from the start of the shutdown procedure (Fig. 7).

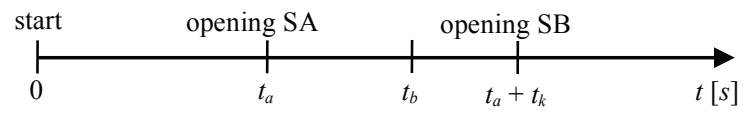

Fig. 7. Procedure for turning OFF the mechanical switch.

In the period between the opening of contacts $\mathrm{SA}$ and $\mathrm{SB}$ (when $t_{a}<t<t_{a}+t_{k}$ ), the disconnect operation on triac $\mathrm{T}_{1}$ is realised. This operation occurs because of the power interruption on the transmitting diode in optotriac $\mathrm{T}_{2}$. The main circuit is disconnected using triac $\mathrm{T}_{1}$ only at the time $t_{b}$. This time is the moment in which the sine wave of the current flowing through $\mathrm{T}_{1}$ is equal to zero. Subsequently at $t=t_{a}+t_{k}$, contact $\mathrm{SB}$ is opened. This causes the isolation of the receiver on the phase conductor L from the power source. 


\section{Observations of electrical signals on an experimental model}

The purpose of these measurements in the test device is determine the voltage waveforms as a function of time. The device according to Fig. 6 has been assembled. Resistive element has been used as a receiver. Waveforms were measured: the power supply voltage $U_{p}$, the logical state of the contacts SA and SB, and the voltage at the receiver $U_{0}$. AC / DC measuring card was used to record the waveforms. The team of mechanical contacts SA and SB was made using two electromagnetic relays.

The required $t_{k}$ delay time is the time between the start of the current flow through the coil of the relay and the closing of the relay contacts (approx. $4 \mathrm{~ms}$ ). This time depends on the value of the current that flows through the coil. Resistive type receiver was used. The observed results are shown in Fig. 8.

Activation of triac $\mathrm{T}_{1}$ is done when three conditions are met (Fig. 8):

- The wave of $U p$ signal passes through zero,

- $\quad \mathrm{SA}$ and SB is in the attached state.

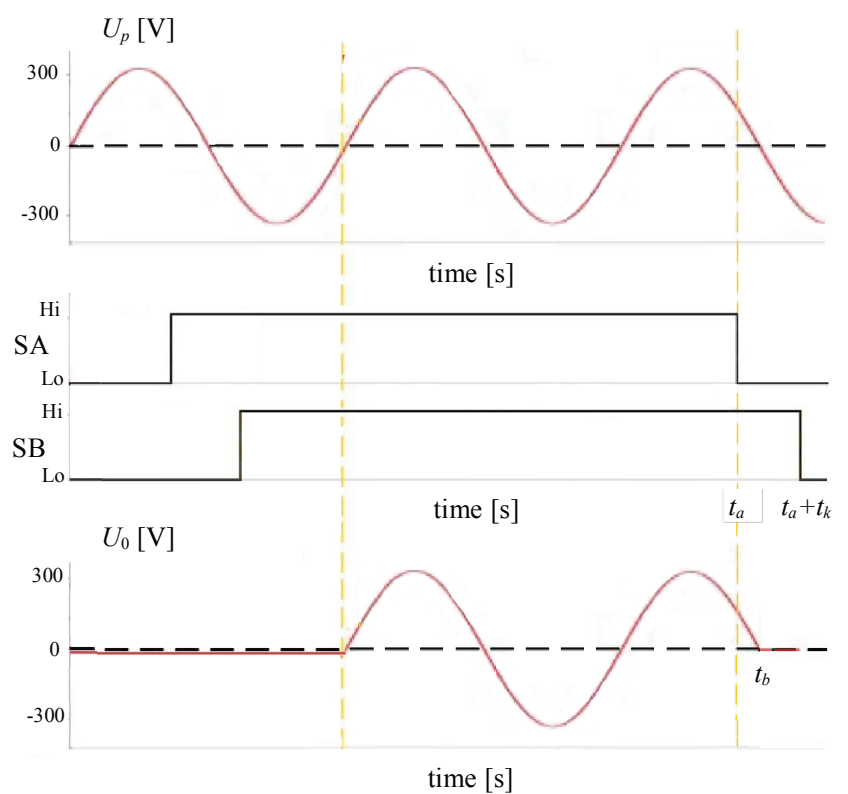

Fig. 8. The selected electrical waveforms in the circuit, where: $t_{a}, t_{b}, t_{a}+t_{k}$ points according to Fig. 7, $U_{p}-$ voltage power source, SA \& SB - logical state of the contacts, $U_{0}$ - voltage at the receiver

Deactivation of triac $T_{1}$ is done when (Fig. 8):

- $\quad$ SA switch are transfered in the open state,

- Sinusoidal waveform of the current flowing through the triac (see $U_{0}$, when the receiver is resistive) reaches a value equal to zero.

After disconnection of triac $\mathrm{T}_{1}$ followed by opening the contact SB. This operation occurs at zero current.

\section{Cooperation of the device with a receiver}

The hybrid switch is installed in a circuit with low voltage AC power and with the phase conductor in series with the receiver. The value for the minimum and maximum power of the receiver depends on the type of installed diode $\mathrm{D}_{1}$.

In place of the diode $\mathrm{D}_{1}$, it is possible to use a linear resistance with a suitably selected resistance value and power. It is a solution that should be dedicated to a specific electrical device.

\section{Conclusions}

The discussed hybrid switch $[14,15]$ is a series connection of the mechanical switch (SB) and triac switch $\left(T_{1}\right)$. It enables the realisation of the commutation process under the conditions required for an insulating switch. No ignition of an electric arc during the commutation occurs only when the conditions are right: Fig. 3 - when switching ON, Fig. 7 - when switching OFF. Switching ON and OFF is performed at the time when the transition sinusoidal current goes through zero. This results in an improved switching process, resulting in an increased uptime hybrid switch and improving the working conditions of the electrical equipment powered from a common main.

Diode $D_{1}$ is plugged in series with the power circuit receiver and causes a slight decrease in the supply voltage. The energy needed to power this switch is taken directly from the current path. Therefore, the third wire ( $\mathrm{N}$ in Fig. 6) connecting the power supply with the switch is not required. The hybrid switch is coupled by using two terminals in series with the receiver and the source similar to the embodiment of a conventional switch (e.g., switch placed in the wall of the house to the light switch). The hybrid switch is a device that can be easily replaced, and it can replace conventional switches that are recessed without modifications of the domestic electrical installation. When powered OFF, the switch does not receive power from the source.

The failure of the hybrid switch does not cause problems for the user. In the event of damage to diode $\mathrm{D}_{1}$ or triac $\mathrm{T}_{1}$, the switch will continue to function as a conventional switch without limiting the overvoltages. Increasing the complexity of the hybrid switch will result in increased costs of production. According to the preliminary estimates, the increase will be approximately $50 \%$ of the sales in the first phase and will gradually decrease with an increase in demand for this product.

\section{References}

1. Y. Lizhi, L. Guishu, S. Haifeng, L. Xin, L. Xixiao, Lightning (APL), 7th Asia-Pacific International Conference, 727-730 (2011) 
2. J. Magnusson, R. Saers, L. Liljestrand, G. Engdahl, IEEE Trans. Power Electron. 29, 6, 2715-2722 (2014)

3. H. Shareef, S.N. Khalid, M.W. Mustafa, A. Mohamed, IEEE Int. Conf. Power and Energy Conference, p.357-361 (2008)

4. Z. Tao, S. Liu Xue, Z. Yin, S. Peng, IEEE Int. Conf. Applied Superconductivity and Electromagnetic Devices, 430-431 (2013)

5. K. Zajkowski, Neural Comput. Appl. 24, 2, 431-439 (2014) DOI: 10.1007/s00521-012-1239-0

6. S. Duer, K. Zajkowski, R. Duer, J. Paś, Neural Comput. Appl. 23, 3-4, 913-925, (2013) DOI: 10.1007/s00521-012-1016-0

7. S. Duer, K. Zajkowski, Neural Comput. Appl. 23, 78, p.2185-2197, (2013) DOI: 10.1007/s00521-0121169-x

8. F. Wu, B. Sun, K. Zhao, and L. Sun, IEEE Trans. Ind. Electron. 60, 10, 4450-4457 (2013)
9. M. Siergiejczyk, J. Paś, A. Rosiński, IET Intell. Transp. Syst. 10, 9, 587-593 (2016)

10. J. Paś, M. Siergiejczyk, Diagnostyka, 17, 1, 49-55, (2016)

11. W. Choromański, J. Dyduch, J. Paś, Archives of Transport, Polish Academy of Sciences, 23, 2, 137152, Warsaw (2011)

12. S. Duer, K. Zajkowski, I. Płocha, R. Duer, Neural Comput. Appl. 22, 7-8, 1581-1590, (2013) DOI: $10.1007 / \mathrm{s} 00521-012-1052-9$,

13. W. Deluga, Annu. Set Environ. Prot. 15, 944-965, Koszalin (2013)

14. K. Zajkowski, patent for invention No. P.406646, Polish Patent Office, Protection for: Koszalin University of Technology (2016)

15. K. Zajkowski, patent for invention No. P.406647, Polish Patent Office, Protection for: Koszalin University of Technology (2016) 